IZA DP No. 3219

International J ob Search:

Mexicans In and Out of the US

Sílvio Rendon

Alfredo Cuecuecha

December 2007 


\title{
International Job Search: Mexicans In and Out of the US
}

\author{
Sílvio Rendon \\ Stony Brook University \\ and IZA \\ Alfredo Cuecuecha \\ ITAM
}

\author{
Discussion Paper No. 3219 \\ December 2007
}

\author{
IZA \\ P.O. Box 7240 \\ 53072 Bonn \\ Germany \\ Phone: +49-228-3894-0 \\ Fax: +49-228-3894-180 \\ E-mail: iza@iza.org
}

\begin{abstract}
Any opinions expressed here are those of the author(s) and not those of the institute. Research disseminated by IZA may include views on policy, but the institute itself takes no institutional policy positions.

The Institute for the Study of Labor (IZA) in Bonn is a local and virtual international research center and a place of communication between science, politics and business. IZA is an independent nonprofit company supported by Deutsche Post World Net. The center is associated with the University of Bonn and offers a stimulating research environment through its research networks, research support, and visitors and doctoral programs. IZA engages in (i) original and internationally competitive research in all fields of labor economics, (ii) development of policy concepts, and (iii) dissemination of research
\end{abstract} results and concepts to the interested public.

IZA Discussion Papers often represent preliminary work and are circulated to encourage discussion. Citation of such a paper should account for its provisional character. A revised version may be available directly from the author. 
IZA Discussion Paper No. 3219

December 2007

\section{ABSTRACT}

\section{International Job Search: Mexicans In and Out of the US}

It is argued that migration from Mexico to the US and its corresponding return migration are determined by international wage differentials and preferences for origin. We use a model of job search, savings and migration to show that job turnover is a crucial determinant of the migration process. We estimate this model by Simulated Method of Moments (SMM) and find that migration practically disappears if Mexico has American arrival rates while employed. Doubling migration costs reduces migration rates in half, while subsidizing return migration in $\$ 300$ reduces migration rates of older migrants but increases migration rates of younger migrants.

JEL Classification: F22, J64, E20

Keywords: international migration, job search, job turnover, savings, structural estimation

Corresponding author:

Sílvio Rendon

Economics Department

Stony Brook University

Stony Brook, NY 11794-0001

USA

E-mail: srendon@ms.cc.sunysb.edu

\footnotetext{
* We thank participants of seminars at ITAM, U. of San Andrés, Torcuato di Tella, U. of Rochester, $U$. at Albany, Boston College, U. of Western Ontario, and at the LACEA conference in Mexico, ESPE conference in Chicago, the North American Summer Meetings of the Econometric Society in Durham. Financial support of the Mexican Association of Culture is gratefully acknowledged. The usual disclaimer applies.
} 


\section{Introduction}

International migration between two countries is a process whereby migrants cross borders bidirectionally, frequently and from old. ${ }^{1}$ Mexico and the US are two neighboring countries with a particularly intensive dynamics of migration and return migration: in year 2000 Mexican migrants in the US represent above $10 \%$ of the Mexican labor force, many of which return back to Mexico. ${ }^{2}$ It is argued that this migration process depends basically on international wage differentials and preferences for origin. In this paper we use a model of job search, savings and migration to show that migration and return migration heavily depend not just on wage differentials or preferences, but also on job turnover and, in particular, on job-to-job transitions. To a great extent, Mexicans migrate to the US seeking mobility, which they do not totally find in their own country.

This is the first paper to explain international migration in close connection with the process of job search. We propose a model in which individuals search for jobs and accumulate wealth in two labor markets. We estimate this model to match observed patterns of migration, wage growth and job turnover in Mexico and the US and analyze several potential regime changes. Our main result is that a more dynamic labor market in Mexico, assigning Mexico the US arrival rates while employed, reduces migration rates from Mexico to the US to very low levels. Migration from Mexico is caused by faster mobility, not just by higher wages in the US. ${ }^{3}$ This decrease in

\footnotetext{
${ }^{1}$ In 1908-1910 on average $32 \%$ of immigrants to the US returned to their countries (Piore 1979). Between 1960 and 1970 half of the annual flow of immigrants to the US returned home (Warren and Peck 1980). In fact, temporary migration is important for many countries (Dustmann, 2003). Aydemir and Robinson (2006) document outmigration rates in several countries, ranging between $22 \%$ and $55 \%$. This process is very specific to the country of destination, for example, in Canada outmigration flows go to a third country, and highly heterogeneous by country of origin (Jasso and Rosenzweig 1982).

${ }^{2}$ Available studies estimate migration rates of $11.68 \%$ (Chiquiar and Hanson 2005) and return migration rates of $42.6 \%$ (Jasso and Rosenzweig (1982) and 66\% (Reyes 1997).

${ }^{3}$ Mexico has a more flexible labor market in terms of job turnover than other Latin-American countries, which have similar labor market regulations (Maloney 1997, Frenkel and Ross 2004); it is however less flexible than other OECD and industrial countries (Calderon-Madrid 2000, Heckman and Pages-Sierra 2000).
} 
migration is substantially larger than the one produced by a comparable increase in wage offers in Mexico. On the other hand, doubling migration costs from Mexico to the US reduces migration rates at age 25 from $21 \%$ to $11 \%$, while subsidizing return migration in $\$ 300$ reduces migration rates of older cohorts, from $12 \%$ to $9 \%$ at age 45, but increases migration rates of younger cohorts, from $1 \%$ to $2 \%$ at age 15 .

These new results come from analyzing jointly migration turnover and job search dynamics. So far, migration has been explained by mechanisms based on international wage differentials, ${ }^{4}$ which only generate one-directional migration (Sjaastad 1962) To explain return migration the literature has extended these mechanisms to allow for incomplete information, heterogeneity in preferences for origin, and higher returns to capital or human capital in origin countries. ${ }^{5}$ These type of migrants are typically called target savers (Massey et al.) and these models life cycle explanations (Yang 2006). Thus, the literature has evolved to analyze migration using dynamics models that allow for bidirectional migration over the life cycle. Interestingly, most of these models focus their attention in the formation and impact of social networks formed by migrants (Delechat 2001, Angelucci 2002, Haslag, Guzman and Orrenious 2004, Colussi 2006, Kennan and Walker 2006, Gemici 2007).

Delechat finds that the probability of working in the US increases with the own personal US experience, as well as with the existence of family migrant networks and larger migration prevalence in the community. Angelucci (2002) estimates a dynamic model of migration in which higher migration costs will deter some people

\footnotetext{
${ }^{4}$ These mechanisms are unemployment or wage differentials (Harris and Todaro 1970), expected wages, probabilities of employment and tax rates, and the probability of being deported in the destination country (Todaro and Maruszko 1987), adverse selection and poverty traps (Bencivenga and Smith 1997).

${ }^{5}$ Incomplete information can be of job searchers about the destination labor market (Herzog and Schottman 1982) or of employers about the quality of workers (Katz and Stark 1987, Hendricks 2001). Heterogeneity can be of migrants in preference for origin (Hill 1987, Djajic and Milbourne 1988, Raffalhüschen 1992, Cuecuecha 2006) or in aversion to inequality in a context of incomplete insurance markets (Stark 1984, Stark and Yitzhaki 1988). Higher returns in origin countries can be to physical capital (Borjas and Bratsberg 1996, Lindstrom 1996) or to human capital (Dustmann and Kirchkamp 2002), as looser credit constraints (Mesnard 2004) or as higher purchasing power (Dustmann 1997, Stark, Helmenstein and Yegorov 1997, Dustmann 2003). Actually, some authors base their explanations on several of these mechanisms (Yang 2006).
} 
from migrating, but it will also increase migrants' duration in the US. Haslag et al. (2004) propose an overlapping generations model in which individuals can invest in the formation of social capital, which depends on the number of people from the family that are in the US and in the investment they made in the network. The network here provides not only with job offers in the US, but also with transfers when old. Colussi (2006) estimates a dynamic general equilibrium model of migration and finds that the existence of networks generates an S-shaped migration process, in which migration first increases at an increasing rate and then slows down. He also shows that increasing migration costs increase migration levels as individuals stay longer in the US. Kennan and Walker (2006) propose a model of migration to several locations with specific income prospects; thereby, migration dynamics is conceived of actually as a process of search for the best geographical match. Gemici (2007) estimates a model of married couples' migration and employment decisions, finding that migration events tend to occur mostly as a response to men's opportunities.

In our model, agents look for jobs and accumulate wealth in one country, but can move to the neighboring country paying a monetary cost of migration. We estimate this model by Simulated Method of Moments (SMM) to match observed migration and return migration, job search outcomes and turnover in both labor markets. Data come from the Mexican Migration Project (MMP), Mexican and American employment surveys (ENEU and CPS) and the census. Using the recovered behavioral parameters of the model we perform simulations of counterfactual scenarios, characterized by American arrival rates while employed in Mexico, a higher wage offer distribution in Mexico, higher migration costs from Mexico to the US and a subsidy to return migration to Mexico.

The remainder of the paper is organized as follows. The next section explains and characterizes a model of job search, migration and savings; Section 3 describes the different datasets used, as well as the criteria chosen to select the sample and the moments used in the estimation. We also present descriptive statistics for these data. 
Section 4 details the estimation method, a simulated method of moments. Section 5 discusses and interprets the estimation results and provides goodness of fit tests. Section 6 performs counterfactual experiments of improvements of labor markets in Mexico, characterized by higher arrival rates while employed and better wage offers in Mexico, and variations of migration costs. Finally, Section 7 summarizes the paper's main conclusions.

\section{Model}

In this model agents seek to maximize their expected lifetime utility without bequests by choosing their location, consumption and acceptable wage offers. At each period they derive utility of consumption, given by the period-by-period utility function $U(\cdot)$, and enjoy a utility premium $\psi$, when they are in their home country. Agents are active, employed or unemployed, for $T=52$ years (13-65) after which they retire and live off their savings without ever going back to active life, for a maximum of $\bar{T}=75$ years $(15-90)$. Location is denoted by $k(=0,1)$, where 0 stands for their home country, Mexico, and 1 for the destination country, the US. All agents enter active life as unemployed in their home country $(k=0)$ and with an initial stock of wealth $A_{0}$. Before engaging in job search activity an agent has to decide whether to stay in his current location or migrate. If an agent decides to migrate, he has to pay a relocation-specific-migration cost $c^{k}$ and enters the new labor market as unemployed. Agents can always switch location, but only throughout their working lifetime they can experience employment transitions.

Conditional on their wealth $A_{t}$, their location, and their employment status agents decide how much to consume $C_{t}$, therefore their desired level of wealth for the next period $A_{t+1}$, and their employment transitions. They have a subjective discount factor is $\beta \in(0,1)$, can save at rate of return $r$, but cannot borrow. ${ }^{6}$ When unemployed,

\footnotetext{
${ }^{6}$ The 'natural' borrowing limit under free capital markets is set at the level which individuals can repay back with probability one. In this setup, however, because agents can move from one location
} 
conditional on their location, they receive a wage offer with age-dependent probability $\lambda_{t}^{k}$, drawn from a wage offer distribution $F^{k}(\cdot),(x \in(\underline{w}, \bar{w}), 0<\underline{w}<\bar{w}<\infty)$. Unemployed agents receive transfers $b^{k}$, which include non-labor income, like family transfers, plus unemployment compensation net of out-of-pocket search costs. When employed, they get laid off with probability $\theta_{t}^{k}$ and with probability $\pi_{t}^{k}$ they receive a wage offer drawn from the same distribution $F^{k}(\cdot)$. Arrival and layoff rates $q_{t}^{k}$, $q=\{\lambda, \pi, \theta\}$, and wages $w_{t}(\omega, k)$ are age- and location- specific, both in initial level as in growth rates. While unemployed, they become employed if they receive and accept a wage offer; otherwise they remains unemployed. While employed, they change employer when they receive an offer and accept it; they stay working for the same employer when they are not laid off, receive an offer that they do not accept or no offer at all, and the current job is preferable to unemployment; they can always quit to become unemployed.

The present discounted utility $V_{t}^{R}$ of a retired agent of age $t\left(=T+1, \ldots, T_{F}\right)$, wealth holdings $A_{t}$, and location $k$ is

$$
V_{t}^{R}\left(A_{t}, k\right)=\max _{\{A\}_{s=t+1}^{T_{F}}} \sum_{s=t}^{T_{F}} \beta^{s-t}\left[U\left(A_{s}-\frac{A_{s+1}}{1+r}\right)+(1-k) \psi\right]
$$

where, in the absence of bequest motives, $A_{T_{F}+1}=0$. With agents saving voluntarily for retirement, with full control over their pension funds, the dynamic problem becomes 'a cake-eating problem.' ${ }^{7}$ The solution to this problem is contained in the wealth accumulation rule $A_{t+1}^{R}\left(A_{t}\right){ }^{8}$

to the other and never come back, this borrowing limit is zero: there is no way to guarantee debt repayment.

${ }^{7}$ The institutional mechanisms of a pension system (characterized by schemes of contribution during working lifetime and pensions during retirement) are beyond the goal of this paper. This highly stylized analysis, however, will prove able to generate savings for life-cycle motives.

${ }^{8}$ Notice that under certain utility functions and $\beta(1+r)<1$ retirees will monotonically run down their assets until they are zero. If retirees can still migrate to enjoy $\psi$, they will prefer to do that early on, actually before they retire, because later their assets will go down over time. Thus, if they have not changed location until they reached retirement age, they will not migrate when they are retired. Location at retirement is an absorbing state. 
International Job Search. Rendon and Cuecuecha. December 2007

Expected lifetime utility $V_{t}^{u}$ in the unemployment state at age $t(=1, \ldots, T)$, wealth holdings $A_{t}$, and location $k$ is defined as

$$
\begin{aligned}
V_{t}^{u}\left(A_{t}, k\right)= & \max _{A_{t+1}^{u} \geq 0}\left\{U\left(A_{t}+b^{k}-\frac{A_{t+1}^{u}}{1+r}\right)+(1-k) \psi\right. \\
& \left.+\beta \max \left[W_{t+1}^{u}\left(A_{t+1}, k\right), W_{t+1}^{u}\left(A_{t+1}-c^{k}, 1-k\right)\right]\right\},
\end{aligned}
$$

where

$$
W_{t}^{u}\left(A_{t}, k\right)=\lambda_{t}^{k} \int \max \left[V_{t}^{e}\left(A_{t}, x, k\right), V_{t}^{u}\left(A_{t}, k\right)\right] d F^{k}(x)+\left(1-\lambda_{t}^{k}\right) V_{t}^{u}\left(A_{t}, k\right) .
$$

In the employment state, expected lifetime utility $V_{t}^{e}$ at age $t(=1, \ldots, T)$, wealth holdings $A_{t}$, wage $\omega$, and location $k$ is

$$
\begin{aligned}
V_{t}^{e}\left(A_{t}, \omega, k\right)= & \max _{A_{t+1}^{e} \geq 0}\left\{U\left(A_{t}+w_{t}(\omega, k)-\frac{A_{t+1}^{e}}{1+r}\right)+(1-k) \psi\right. \\
& \left.+\beta \max \left[W_{t+1}^{e}\left(A_{t+1}, \omega, k\right), W_{t+1}^{u}\left(A_{t+1}-c^{k}, 1-k\right)\right]\right\},
\end{aligned}
$$

where

$$
\begin{aligned}
W_{t}^{e}\left(A_{t}, \omega, k\right)= & \left(1-\theta_{t}^{k}\right)\left(\pi_{t}^{k} \int \max \left[V_{t}^{e}\left(A_{t}, x, k\right), V_{t}^{e}\left(A_{t}, \omega, k\right), V_{t}^{u}\left(A_{t}, k\right)\right] d F^{k}(x)\right. \\
& \left.+\left(1-\pi_{t}^{k}\right) \max \left[V_{t}^{e}\left(A_{t}, \omega, k\right), V_{t}^{u}\left(A_{t}, k\right)\right]\right) \\
& \left.+\theta_{t}^{k}\left(\pi_{t}^{k} \int \max \left[V_{t}^{e}\left(A_{t}, x, k\right), V_{t}^{u}\left(A_{t}, k\right)\right] d F^{k}(x)+\left(1-\pi_{t}^{k}\right) V_{t}^{u}\left(A_{t}, k\right)\right)\right] .
\end{aligned}
$$

Active agents solve a dynamic problem (DP) with a finite horizon $T$ and a 'salvage value' which is the present discounted utility at retirement: $V_{t}^{u}\left(A_{t}, k\right)=$ $V_{t}^{R}\left(A_{t}, k\right), V_{t}^{e}\left(A_{t}, w, k\right)=V_{t}^{R}\left(A_{t}, k\right)$, at $t=T+1$. Two policy rules $A_{t+1}^{u}\left(A_{t}, k\right)$ and $A_{t+1}^{e}\left(A_{t}, w, k\right)$ solve this problem. Whether the individual is employed or unemployed, there exists a reservation wage that indicates the lowest acceptable wage offer, that is, $\omega_{t}^{*}\left(A_{t}, k\right) \equiv\left\{\omega \mid V_{t}^{u}\left(A_{t}, k\right)=V_{t}^{e}\left(A_{t}, \omega, k\right)\right\}$. Similarly, agents migrate when unemployed, if: $W_{t}^{u}\left(A_{t}-c^{k}, 1-k\right)>W_{t}^{u}\left(A_{t}, k\right)$ and when employed, if: 
International Job Search. Rendon and Cuecuecha. December 2007

$W_{t}^{u}\left(A_{t}-c^{k}, 1-k\right)>W_{t}^{e}\left(A_{t}, \omega, k\right)$. Define $\omega_{t}^{* *}\left(A_{t}, k_{t}\right) \equiv\left\{\omega \mid W_{t}^{u}\left(A_{t}-c^{k}, 1-k\right)=\right.$ $\left.W_{t}^{e}\left(A_{t}, \omega, k\right)\right\}$ and call it the retention wage.

Proposition $1 V_{t}^{e}\left(A_{t}, \omega, k\right)$ and $W_{t}^{e}\left(A_{t}, \omega, k\right)$ are increasing in $\omega$. Thus, the reservation wage property exists both for retention and reservation wages. Proof: In Appendix A1.

Thus the retention wage indicates the lowest wage that keeps individuals in their current location; individuals who are employed at a wage lower than $\omega_{t}^{* *}\left(A_{t}, k\right)$ will migrate. Let the indicator function $I_{t}^{m}\left(A_{t}, k\right) \equiv I\left(W_{t}^{u}\left(A_{t}-c^{k}, 1-k\right)>W_{t}^{u}\left(A_{t}, k\right)\right)$ denote whether an unemployed individual will migrate to the other country.

Proposition 2 If $\pi_{t}^{k}<\lambda_{t}^{k}$, then for an individual with wealth $A_{t}$ and of age $t$ $I_{t}^{m}\left(A_{t}, k\right)=1$, implies $\omega_{t}^{* *}\left(A_{t}, k_{t}\right)>\omega_{t}^{*}\left(A_{t}, k_{t}\right)$ and $\omega_{t}^{*}\left(A_{t}, k_{t}\right)>\omega_{t}^{* *}\left(A_{t}, k_{t}\right)$, implies $I_{t}^{m}\left(A_{t}, k\right)=0, k=0,1$. Proof: In Appendix A1.

That is, if unemployed individuals migrate, so do the employed at low wages, and only individuals employed at high wage stay; on the other hand, if all employed individuals are retained in their current location, so are the unemployed.

Because there are no closed-form solutions, we approximate the policy rules and value functions with a numerical solution attained by discretization of the state and choice space into a grid of points. Appendix A2 provides further details on this procedure. This solution requires assuming specific functional forms:

- constant relative risk aversion (CRRA) utility function $U(C)=\frac{C^{1-\gamma}-1}{1-\gamma}$;

- truncated lognormal wage offer distribution $F_{k}(x): \ln \omega \sim N\left(\mu_{k}, \sigma_{k}^{2} \mid \underline{\omega}, \bar{\omega}\right) ; 0<$ $\underline{\omega}<\bar{\omega}<\infty, k=0,1 ;$

- logistic function for age-dependent arrival and layoff rates: $q_{t}^{k}=\frac{\exp \left(\alpha_{q}^{0 k}+\alpha_{q}^{k} t\right)}{1+\exp \left(\alpha_{q}^{0 k}+\alpha_{q}^{k} t\right)}$, where $q=\{\lambda, \pi, \theta\}, k=0,1$. (In the estimation, we will report $q_{0}^{k}=\frac{\exp \left(\alpha_{q}^{0}\right)}{1+\exp \left(\alpha_{q}^{0}\right)}$ and $a_{q}$, the initial arrival and layoff rates and their associated variation parameters.); 
- wage growth function: $w_{t}(\omega, k)=\omega \exp \left(\alpha_{1}^{k} t+\alpha_{2}^{k} t^{2}\right)$.

We graph reservation and retention wages, as well as the migration indicator function for the unemployed in Figures 1 for Mexico and in Figure 2 for the US. They come from the numerical solution of the model at the estimated parameter values, reported in Section 4, and are evaluated at age 23 .

[Figure 1 here]

Figure 1 is illustrative of the employment and migration dynamics that agents experiment when they are in Mexico. While reservation wages are increasing, retention wages, except for very low levels of wealth, are decreasing in wealth. As agents become wealthier they are more selective in their wage aspirations to become employed, but less demanding in their wage aspirations to stay in their country. Consequently, more wealth increases the hazard rate of becoming employed while decreasing the hazard rate of migrating to the US. At very low levels of wealth, almost zero wealth, employed agents stay in Mexico, even if they are employed at high levels of wages, as migrating is a risky decision, and shy away from being in the US with zero wealth. For them the migration costs is a strong barrier to migration. The same applies to the unemployed with very little wealth, who also stay in Mexico because they cannot pay the migration cost. With some more wealth, between 0 and around 2000 dollars worth of wealth, the unemployed migrate to the US, and with wealth around 7000 dollars worth and above, they stay in Mexico. When agents are employed, they stay at very low levels of wealth, no matter how high their wages are. With some more wealth, agents migrate if wages are low and stay at high wages. And, at high levels of wealth, no agent, employe or unemployed, migrates. That is, the segment that migrates to the US has little wealth and is unemployed or employed at relatively low wages. 
[Figure 2 here]

Figure 2 depicts the employment and migration dynamics of agents who are currently in the US. Unlike in Mexico, while reservation wages are decreasing, retention wages are increasing in wealth. Being wealthier makes agents less selective in their job search, but more selective in their return migration decision. This implies that wealth increases the hazard rate of becoming employed and of returning to Mexico. Like in Mexico, agents with very low wealth levels stay, whether they are employed, no matter at what wage level, or unemployed. Unemployed agents with wealth levels less than 10,000 dollars worth stay in the US, while those with more than that return to Mexico. Like in Mexico, low wage agents return, while, high wage individuals stay.

In sum, in both locations wealth accumulation increases individuals' selectivity in their job and location search: in Mexico it increases their selectivity in job search and retains them in Mexico, while in the US it decreases their selectivity in job search and propels return to Mexico. Consequently, wealth accumulation is a force that keeps individuals in Mexico or, if they are in the US, makes them return to Mexico.

\section{Data}

Data come from five sources: the Mexican Migration Project (MMP103) data set, the Mexican and the US Censuses of 2000, the first to fourth quarters waves of the Mexican Urban Employment survey (ENEU-Encuesta Nacional de Empleo Urbano) for 1999, and the January to December waves of the Current Population Survey (CPS) for 1999. In all these data sets we only consider 15 to 45 year old males, who are not disabled or incarcerated. We also exclude individuals for which there is only one observation, except in the two censuses. In Appendix A3, Table A1, we report how each of these selection criteria reduces the amount of observations in the final sample. 
From the MMP103 we obtain migration rates, flows of Mexicans going into the US and returning from the US and job-to-job transitions. This is the only source of information we are aware of on job-to-job transitions in Mexico and for Mexicans in the US. This is a data base developed by Princeton University and the Universidad de Guadalajara. It surveys 103 communities in 19 Mexican states from 1982 until 2002; it is more representative of rural Mexico. Each year the survey chooses a set of communities that are interviewed during winters, while a follow up survey is done during summers for individuals residing in the US. Our final sample consists of 8,172 individuals.

From the Mexican and American Censuses we obtain annual wage incomes in PPP dollars. We use a $10 \%$ sample of the 2000 Mexican Census. After performing the selection by age, gender, incarceration and disability, we end up with approximately 1.7 million observations to estimate moments from this data set. From the US. Census (IPUMS data base) we use a 5\% sample of Mexicans, which, after applying the mentioned selection filters, reduces to approximately 134 thousand observations

Information on unemployment rates, exit from unemployment, and job loss comes from Mexican and American employment surveys. For Mexico we use the first to fourth quarter waves of the ENEU of 1999, of which we select 113 thousand observations. Unlike the MMP, this data set is representative of urban Mexico. It is a quarterly rotating panel on employment status, employment transitions and wages of individuals. We annualize the observed quarterly transitions under the assumption that transition rates are time independent, that is, we calculate the probability that an individual in a given quarter is observed a year later with a different employment status. For the US we use the CPS 1999, January to December waves, which a representative data set of the US population. It provides also with a rotating panel on employment status, employment transitions and wages of individuals. We only include in the study individuals that claim to be born in Mexico, around 3 thousand individuals. As with the Mexican survey, we annualize the monthly employment 
transitions under the assumption that transition rates are time independent. Further details on the sample selection, the choice of data sources and comparison of our data with those reported in previous studies are provided in Appendices A3-A5.

[Table 1 here]

Table 1 shows migration, wage and unemployment variables by country and age bracket. The migration stock is $12 \%$ among individuals 16 to $25,17 \%$ among individuals 26 to 35 , and $16 \%$ among individuals 36 to 45 . It is also shown that both migration and return migration flows are decreasing, but the former are on average $2.9 \%$, while the latter are on average $13 \%$. The wage gap between Mexico and the US is wide and increasing with age. The standard deviation of log wages decreases with age in the US, while it increases with age in Mexico. Unemployment rates are higher in Mexico than in the US for young cohorts but fall faster in Mexico than in the US, so that for older cohorts they are higher in the US than in Mexico. Something similar happens with exit from unemployment and job loss: initially they are better in the US than in Mexico, but over time they improve in Mexico and end up overtaking those in the US. However, average job-to-job transitions are decreasing and always higher in the US than in Mexico. These transitions will prove to be very important in accounting for the observed migration patterns. We will show that wage differentials and faster job-to-job transitions in the US are an incentive for Mexicans to migrate, but as job taking and job loss transitions improve in Mexico and wealth accumulation occurs, older cohorts prefer to return to Mexico.

\section{Estimation}

The estimation strategy is designed to recover the behavioral parameters of the theoretical model. We assume that individuals start off their careers with a wealth 
level drawn from a parametric initial wealth distribution and, for each parameter set, we compute the policy rules that solve the DP problem and use them to generate simulated careers paths. Then, at each iteration of the parameter computation we construct a measure of distance between the observed and the simulated moments. The estimation is a Simulated Method of Moments (SMM) procedure in which the parameter estimates of the theoretical model are the minimizers of this function.

All individuals start off their careers at age 13, being unemployed, with a wealth level $A_{0}$ drawn from a displaced truncated lognormal initial wealth distribution: $\ln \left(A_{0}+1\right) \sim N\left(\mu_{0}, \sigma_{0}^{2} \mid 0, \bar{A}\right)$. Then we use the model to simulate 50,000 individual trajectories and compute several moments that are matched to the observables. The parameters ${ }^{9}$ to estimate are then the following: $\Theta=\left\{\Theta^{0}, \Theta^{1}, \gamma, C_{\psi}, \mu_{0}, \sigma_{0}\right\}$, with $\Theta^{k}=\left\{b^{k}, \lambda_{0}^{k}, \alpha_{\lambda}, \pi_{0}^{k}, \alpha_{\pi}, \theta_{0}^{k}, \alpha_{\theta}, \mu^{k}, a_{1}^{k}, a_{2}^{k}, \sigma^{k}, c^{k},\right\}$. The moments used in this estimation are the cell-by-cell probability masses for the following migration and employment distributions, as well as wage moments:

1. migration rates and flows (30 years $\times 1$ moment $=30)$,

2. migration and return migration flows $(30$ years $\times 2$ moments $=60)$,

3. wage moments $(30$ years $\times 2$ countries $\times 3$ moments $=180)$,

4. employment status (30 years $\times 2$ countries $\times 1$ moment $=60)$,

5. employment transitions $(30$ years $\times 2$ countries $\times 3$ moments $=180)$.

Thus, there are 510 moments to estimate 16 parameters. The SMM procedure relates a parameter set to a weighted measure of distance between sample and simulated moments:

$$
S(\Theta)=\Delta m^{\prime} W^{-1} \Delta m
$$

where $\Delta m$ is the distance between each sample and simulated moment and $W$ is a weighting matrix. In this research, because our main interest is to fit migration observations, we give these variables absolute priority over the others: we use a

\footnotetext{
${ }^{9}$ We report $C_{\psi}=U^{-1}(\psi)$ to have some intuition about the value of the preference for origin parameter in monetary terms.
} 
diagonal matrix $W$ that weighs migration moments ten times as employment and wage moments. The estimated behavioral parameters are thus $\widehat{\Theta}=\arg \min S(\Theta)$. The identification of the parameters of this function is given by employment and location transitions as well as wage data.

The function is minimized using Powell's method (Presss et al.), which requires only function evaluations, not derivatives. Asymptotic standard errors are calculated using the outer-product gradient estimator.

\section{$5 \quad$ Estimation Results}

In this section, we discuss the parameter estimates and compare graphically and numerically actual and fitted moments. The parameter estimates in Mexico and in the US and their corresponding asymptotic standard errors are reported in Table 2.

[Table 2 here]

These estimated parameters reflect closely the patterns described by the observed moments. Thus, higher estimated unemployment transfers in the US capture higher wages in the US. Arrival and layoffs rates reflect employment transitions: the base arrival rate while unemployed is higher in the US, but its corresponding growth parameter is higher in Mexico, which correspond to the age profile of the exit from unemployment. The same occurs with layoff rates, whose base value is higher in Mexico but experimenting a faster decrease over time. Similarly, as shown by the job-to-job transitions by age, arrival rates while employed are always higher in the US. And, as wages are always higher in the US, the mean, variance and growth parameters of log wages show a higher mean, slightly lower variance in the US than in Mexico and similar wage growth parameters.

The cost of migration is estimated at $\$ 550$, while the cost of return migration at $\$ 20$. Since wealth has been discretized and these parameters are substracted directly 
from wealth values, they are very closely related to the gridsize which amounts to $\$ 600$. We checked whether these values are different from zero and only rejected that the cost of migration were zero. The return migration cost is not significantly different from zero.

Attachment to origin is estimated at around $\$ 1450$, almost half of the annual wage in Mexico for young cohorts (16 to 25 years old). The coefficient of risk aversion is estimated at a low value, 0.56 , while the initial wealth distribution denotes a very high initial wealth. Notice that in this estimation we do not have wealth data, so identification of these parameters only come from the interaction of labor market and migration variables. That is, the initial wealth distribution is basically a way of including unobserved heterogeneity in this estimation.

[Figure 3 here]

Most of the parameter estimates are significant at the $5 \%$ confidence interval. However, it is often the case than in the estimation of structural models standard errors are very low. Accordingly, we provide some extra measures of fit for our estimation, starting with showing figures of how well the model matches the observed moments in the data. Figures $3 \mathrm{a}$ to $4 \mathrm{~h}$ illustrate the results obtained by the estimation.

Figures $3 \mathrm{a}$ and $3 \mathrm{~b}$ show that the observed migration rate and flows are well fit by our predictions, which mimic the inverted U-shaped migration rate and flows and the decreasing return migration patterns. Figures $3 \mathrm{c}$ and $3 \mathrm{~d}$ show that wage levels for Mexico and the US are well replicated by the model, while mean logwages are somewhat underpredicted, as shown in Figures 3e and 3f. The standard deviation of logwages, Figures $3 \mathrm{~g}$ and $3 \mathrm{~h}$, are observed to increase with age in Mexico, while it is observed to decline with age for Mexicans in the US. We predict a fairly stable standard deviation that tends to decrease over time, as it occurs in search models: 
as individuals accumulate wealth, their reservation wage increases and the accepted wage offer distribution is truncated at higher levels (see Rendon 2006, 2007).

[Figure 4 here]

Figure 4 compares actual and predicted employment variables. Replication of unemployment rates is fairly good for Mexicans both in Mexico and in the US, Figures $4 \mathrm{a}$ and $4 \mathrm{~b}$, respectively. The probability of leaving unemployment in Mexico, Figure 4c, is replicated with some overprediction for young cohorts; for older cohorts the predicted level goes down, while the actual levels are pretty stable. This decline in Mexico is caused by Mexicans who return wealthy from the US and are therefore more selective in accepting jobs. For the US, in Figure 4d, replication is pretty good, but with some underprediction for middle-aged agents. As is shown in Figure 4e and 4f, the decreasing pattern of job loss in both countries is fairly well replicated by the model. Job-to-job transitions and their decreasing trend in both countries are also well replicated by the model, however with some underprediction in both cases, in Figures $4 \mathrm{~g}$ and $4 \mathrm{~h}$.

[Table 3 here]

To assess more formally how well the parameter estimates capture the essential features of the data, in Table 3 we compare the observed and the predicted moments and perform goodness of fit tests. The test statistic across discrete choices $j$ at time $t$ is defined as $\chi_{j}^{2}=\Sigma_{t=1}^{30} \frac{\left(p_{j t}-\widehat{p}_{j t}\right)^{2}}{\hat{p}_{j t}}$, where $p_{j t}$ is the actual number of observations of choice $j$ at time $t$, and $\widehat{p}_{j t}$ is the model predicted counterpart. This statistic has an asymptotic $\chi^{2}$ distribution with $T-1$ degrees of freedom. A larger $\chi^{2}$ implies that our model deviates more from the observed moments. Consequently, the null hypothesis tests whether the distance between observed and predicted moments is 
zero, which is clearly rejected. For continuous variables we report the $R^{2}$ statistic defined as $R^{2}=\frac{\sum \widehat{Y}^{2}}{\sum \widehat{Y}^{2}+\sum e^{2}}$, where $\widehat{Y}$ is the predicted variable and $e=Y_{o b s}-\widehat{Y}$ is the predicted error. ${ }^{10}$ Our $R^{2}$ statistics confirm the graphical analysis that our moments match correctly the data

In sum, the estimated model is shown to be able to replicate well the observed patterns in the data. In the next section, we use the model to evaluate the results of variations in the recovered parameters.

\section{Regime Changes}

After recovering the underlying behavioral parameters, we explore how do the predicted trajectories change under alternative scenarios: improvement of labor market conditions in Mexico and migration costs variations. We report the results of these experiments in Figures 5 and 6 and in Table 4.

[Table 4 here]

Our first exercise consists of assigning Mexico the US arrival rates while employed at all ages. The mean estimated arrival rate while employed in the US is 0.77 , while its Mexican counterpart is 0.17 ; consequently this exercise increases the arrival rates while employed in Mexico by a factor of 3. Column 1 in Table 4 shows the results of this exercise for selected estimated moments. The results in terms of migration rates are striking: the highest migration rate observed at any age drops by $90 \%$, from $21 \%$ at age 25 , to $2 \%$ at age 30 . Migration at age 15 disappears, while migration by age 45 is $1 \%$. This is the result of a dramatic reduction in the annual flows of immigrants and an increase in the return migration flows. The highest migration flow falls by $88 \%$, from $6 \%$ at age 23 to $1 \%$ at age 28 , while the highest return migration flow increases

\footnotetext{
${ }^{10}$ Unlike in the linear regression framework, this statistic is not bounded between zero and one, because it is not necessarily true that $\sum \widehat{Y} e=0$.
} 
$65 \%$ from $22 \%$ at age 17 to $37 \%$ at age 29 . These changes in migration rates generate a reduction of $64 \%$ in the average duration of migration and a reduction of $37 \%$ in the mean number of times that individuals need to spend in the US. We also observe that as individuals change jobs more frequently, wages increase $42 \%$ at age 45 . Similarly the unemployment rate at age 45 declines $63 \%$, exit from unemployment increases $41 \%$, job separations diminish $11 \%$ and job to job transitions increase $85 \%$.

Our second exercise is an increase in mean wages offers in Mexico of $42 \%$. This exercise allows us to assess the migration response to economic growth in Mexico in a way that is comparable to the first experiment, which also increases wages, so that we can disentangle effects of wage increases from effects of arrival rates' increases. Column 2 in Table 4 shows that the increase in Mexican wages reduces the net migration rate and the Mexico-US flows, while it increases the US-Mexico flows. However, these changes are in all cases smaller than the changes produced in our first exercise, except for the case of return migration rates.

[Figure 5 here]

Figure 5 shows the net migration rates, the Mexico-US flows and US-Mexico flows for all ages for the benchmark case, our exercise number 1 and exercise number 2 . We can clearly see that the effect of imposing US arrival rates in Mexico is strikingly higher than the effect of increasing the mean wages in Mexico. This is generated by the fact that Mexico-US flows are sharply reduced and represent the lowest flows of the three cases depicted, and by the fact that return flows increase for all ages above 20 years old. Notice that for very young individuals return migration rates go to zero simply because the migration flows are reduced to zero.

Our third exercise consists in doubling the costs of migrating from Mexico to the US. Column 3 in Table 4 shows that this experiment reduces all migration moments that we consider in our simulation and that such reductions are smaller than our 
discussed changes with the arrival rate of the US. Column 4 in Table 4 performs our last exercise that consists in giving a subsidy of 300 dollars for migrants to go home. We can see that this policy produces the lowest reduction in migration. The main reason is that this policy reduces migration of the old, but increases migration of young individuals.

[Figure 6 here]

Figure 6 compares the migration rate, the Mexico-US flow and the US-Mexico flow for the benchmark case, and the two migration costs variations exercises. These figures show clearly that compared to the increase in migration costs a subsidy to return migration is the worst policy if the objective is to reduce migration.

In sum, among the four exercises carried out here, the improvement in labor markets due to the use of the US arrival rate while employed in the Mexican labor market is the one that generates the largest reductions in migration rates. This reveals that migration from Mexico to the US is not only generated by higher wages but also by faster mobility in the latter country. On the other hand, increasing migration costs is very effective in reducing migration from Mexico to the US.

\section{Conclusions}

We propose a model of job search, savings and migration that is able to replicate the main trends of the data. Marked differences in wage and job-to-job transitions persist between Mexico and the US, but job taking and job loss transitions tend to converge and become relatively better in Mexico. Accordingly, individuals choose to migrate when young to save in the US and return home at a mature age, when they are wealthier, labor market conditions improve in Mexico, and they can enjoy non-pecuniary benefits from living in their home country. 
Our experiments on regime changes show that assigning Mexico the US arrival rates while employed results in a dramatic reduction in migration rates, practically to zero. This regime change is more powerful than a comparable increase in the Mexican wage offer distribution. Doubling migration costs does reduce migration substantially, but not as much as an increase in arrival rates while employed. Subsidizing return of Mexican migrants reduces migration of older cohorts, but increases migration of younger cohorts.

We interpret our results as indicative that Mexicans migrate not just attracted by higher wages but also by faster mobility in the US. A more dynamic labor market in Mexico, i.e. one with faster job reallocations, would dramatically reduce migration to the US. 


\section{Appendix}

\section{A1. Proofs of Propositions 1 and 2}

Proof of Proposition 1: At age $t=T, V_{t}^{e}\left(A_{t}, \omega, k\right)$ is monotonically increasing in $\omega$. This follows from the fact that the utility function is increasing in consumption and a higher $\omega$ increases consumption at time $T$. Then $W_{T}^{e}\left(A_{T}, \omega, k\right)$ defined in is also increasing in $\omega$. Now, functions $V_{t}^{e}\left(A_{t}, \omega, k\right)$ and $W_{t}^{e}\left(A_{t}, \omega, k\right)$ at $t<T$ preserve monotonicity in $\omega$. Thus the reservation wage property exists both for reservation and retention wages

Proof of Proposition 2: If $\pi_{t}^{k}<\lambda_{t}^{k}$, then $W_{t}^{u}\left(A_{t}, k\right)>W_{t}^{e}\left(A_{t}, \omega^{*}\left(A_{t}, k\right), k\right)$ and from the definition of retention wages we know that $W_{t}^{e}\left(A_{t}, \omega^{* *}\left(A_{t}, k\right), k\right)=W_{t}^{u}\left(A_{t}-c^{k}, 1-k\right)$.

Then $I_{t}^{m}\left(A_{t}, k\right)=1$ is equivalent to $W_{t}^{u}\left(A_{t}-c^{k}, 1-k\right)>W_{t}^{u}\left(A_{t}, k\right)$ and because of transitivity $W_{t}^{e}\left(A_{t}, \omega^{* *}\left(A_{t}, k\right), k\right)=W_{t}^{u}\left(A_{t}-c^{k}, 1-k\right)>W_{t}^{u}\left(A_{t}, k\right)>W_{t}^{e}\left(A_{t}, \omega^{*}\left(A_{t}, k\right), k\right)$. Hence $\omega_{t}^{* *}\left(A_{t}, k_{t}\right)>\omega_{t}^{*}\left(A_{t}, k_{t}\right)$. Similarly, $\omega_{t}^{*}\left(A_{t}, k_{t}\right)>\omega_{t}^{* *}\left(A_{t}, k_{t}\right)$ is equivalent to $W_{t}^{e}\left(A_{t}, \omega^{*}\left(A_{t}, k\right), k\right)>W_{t}^{e}\left(A_{t}, \omega^{* *}\left(A_{t}, k\right), k\right)$ and because of transitivity $W_{t}^{u}\left(A_{t}, k\right)>$ $W_{t}^{e}\left(A_{t}, \omega^{*}\left(A_{t}, k\right), k\right)>W_{t}^{e}\left(A_{t}, \omega^{* *}\left(A_{t}, k\right), k\right)=W_{t}^{u}\left(A_{t}-c^{k}, 1-k\right)$. Hence, $I_{t}^{m}\left(A_{t}, k\right)=$ 0

\section{A2. Numerical Solution of the Model}

As mentioned in the main body of the paper, the model is solved on a discretized state space. The table below gives further details of this discretization, based on Rendon (2006).

\begin{tabular}{lrr}
\hline \hline & Discretization of variables \\
\hline \hline Original Variable & Assets & Wages \\
Discretized Variable & $A$ & $\omega$ \\
Gridpoints & $A(i)$ & $\omega(j)$ \\
Number of Gridpoints & $i=1, \ldots, N_{A}$ & $j=1, \ldots, N_{w}$ \\
Lower Bound & $N_{A}=251$ & $N_{w}=51$ \\
Upper Bound & $\underline{A}=0$ & $\underline{w}=50$ \\
Gridsize & $\bar{A}=150,000$ & $\bar{w}=20,000$ \\
\hline \hline
\end{tabular}

The discrete probability for a wage draw $\omega(j)$ is

$$
\widehat{f}(j, k)=\frac{\Phi\left(\frac{\ln \omega(j)+\Delta_{w} / 2-\mu^{k}}{\sigma_{w}^{k}}\right)-\Phi\left(\frac{\ln \omega(j)-\Delta_{w} / 2-\mu^{k}}{\sigma_{w}^{k}}\right)}{\Phi\left(\frac{\ln \bar{w}-\mu^{k}}{\sigma_{w}^{k}}\right)-\Phi\left(\frac{\ln \underline{w}-\mu^{k}}{\sigma_{w}^{k}}\right)} .
$$

Wage as a function of age $w_{t}(\omega, k)$ is also discretized and becomes $w(j, k, t)=\omega(j) \exp \left(\alpha_{1}^{k} t+\alpha_{2}^{k} t^{2}\right)$. Arrival and layoff rates are $q(k, t)=\frac{\exp \left(\alpha_{q}^{0 k}+\alpha_{q}^{k} t\right)}{1+\exp \left(\alpha_{q}^{0 k}+\alpha_{q}^{k} t\right)}, q=$ $\{\lambda, \pi, \theta\}$.

The numerical solution proceeds in the following steps:

1. For $t=T+1$ define the discretized value functions:

$$
\begin{aligned}
V^{u}[i, k, t] & =V^{R}[i, k, t], \text { and } \\
V^{e}[i, j, k, t] & =V^{R}[i, k, t],
\end{aligned}
$$


where $V^{R}[i, k, t]$ is the discretized value of being retired:

$$
V^{R}[i, k, t]=\max _{m}\left\{U\left(A_{s}(i)-\frac{A_{s+1}(m)}{1+r}\right)+(1-k) \psi+\beta V^{R}[i, k, t+1]\right\},
$$

with $A_{T_{F}+1}=0$.

2. Integration. Define the discretized expected values

$$
\begin{aligned}
W^{u}[i, k, t]= & \lambda(k, t) \sum_{j=1}^{N_{w}} \max \left[V^{e}[i, j, k, t], V^{u}[i, k, t]\right] f(j, k)+[1-\lambda(k, t)] V^{u}[i, k, t] ; \\
W^{e}[i, j, k, t]= & {[1-\theta(k, t)]\left(\pi(k, t) \sum_{l=1}^{N_{w}} \max \left[V^{e}[i, j, k, t], V^{e}[i, l, k, t], V^{u}[i, k, t]\right] f(l, k)\right.} \\
& \left.+[1-\pi(k, t)] \max \left[V^{e}[i, j, k, t], V^{u}[i, k, t]\right]\right) \\
& +\theta(k, t)\left(\pi(k, t) \sum_{l=1}^{N_{w}} \max \left[V^{e}[i, l, k, t], V^{u}[i, k, t]\right] f(l, k)\right. \\
& +[1-\pi(k, t)]) V^{u}[i, k, t] .
\end{aligned}
$$

3. Compute the value function for the previous period

$$
\begin{aligned}
V^{u}[i, k, t]= & \max _{m}\left\{U\left(A(i)+b^{k}-\frac{A(m)}{(1+r)}\right)+(1-k) \psi\right. \\
& \left.+\beta \max \left[W^{u}[m, k, t+1], W^{u}[h(m, k), 1-k, t+1]\right]\right\}, \\
V^{e}[i, j, k, t]= & \max _{n}\left\{U\left(A(i)+w(j, k, t)-\frac{A(n)}{(1+r)}\right)+(1-k) \psi\right. \\
& \left.+\beta \max \left[W^{e}[n, j, k, t+1], W^{u}[h(n, k), 1-k, t+1]\right]\right\},
\end{aligned}
$$

where $h(m, k)=\left\{h \mid A(h) \geq A(m)-c^{k}>A(h-1)\right\}$. The maximizers to these problems are $m^{*}=m^{*}(i, k, t)$ and $n^{*}=n^{*}(i, j, k, t)$; and the reservation wage is $j^{*}(i, t)=\left\{j \mid V^{e}[i, j, k, t] \geq V^{u}[i, k, t]>V^{e}[i, j-1, k, t]\right\}$.

4. Go to step 2. This process goes backwards and it is repeated until reaching period $t=1$.

\section{A3. Sample Selection and Construction of Variables}

The first data set used in this paper is the Mexican Migration Project 103; the files used in this paper are the longitudinal files, which include 15,379 individuals. After applying our selection criteria, only males 15 to 45 years old who are not disabled or incarcerated, our sample reduces to 8,172 individuals, as seen in Table A1.

The MMP 103 includes all individuals surveyed in the communities that reaches, which generates three types of observations: those who never migrate and provide their labor history in Mexico; those who migrate, return home, and provide their labor and migration history; and those who migrate, stay in the US, and have some family members in Mexico that provide part of their data. For these individuals, the MMP sends surveyors to the US and interviews those individuals to obtain their labor and migration histories. Consequently, 
the MMP only looses individuals that belong to households that migrated entirely to the US or to another community in Mexico. The longitudinal files of MMP03 are constructed by interviewing individuals and asking them retrospective questions about their migratory history and entire job search history. They are also asked about their first and last wages in both Mexico and the US. We obtain from this data set the migration rate by age and changes in jobs by individuals also by age. To calculate the migration rate by age we obtain the proportion of individuals of a given age that where located in the US, regardless of the calendar year in which that individual is located. By doing so, we average out the migration rate across the 103 communities and across time. We do this to maximize the number of observations by age that qualify with all our selection criteria. The change in jobs variable is obtained from the labor history of the individuals. We obtain this measure by using an indicator variable for the event change in job reported by the individual, conditional on the individual reporting to be employed in the previous year. We then obtain the proportion of individuals of a given job that report changing jobs, conditional on being employed the previous period. We are not aware of any other data set that contains this measure for Mexican individuals. The major disadvantage of the MMP103 data set is the potential measurement error due to recall bias, as well as the fact that over time changes are due not only to individual changes, but they are also due to changes in the communities sampled. Our measure of job to job transition can also miss unemployment spells that lasted less than a year.

The second data set is a $10 \%$ sample of the 2000 Mexican Census. Here we are using the files containing 4.9 million observations on Mexican males. Once we restrict attention to individuals 15 to 45 years old and exclude disabled people we are left with 1.7 million observations, as shown in Table A1. ${ }^{11}$ We obtain annual wage income multiplying by twelve the monthly income reported in the census and then dividing by 9.6, which was the average nominal exchange rate peso-dollar in 2000.

The third data set is a 5\% sample of the US census (IPUMS data base), which has 234 thousand observations on individuals that claim to be born in Mexico. Once we restrict the sample to males 15 to 45 years old and exclude disabled individuals we are left with 134 thousand observations (see Table A1).

The fourth data set used in the paper is the ENEU 1999 first quarter to fourth quarter waves. ENEU is representative of urban Mexico. It includes a total of 495 thousand individuals. Once we restrict attention to males between 15 to 45 years old and exclude the disabled, we are left with 112 thousand individuals. ${ }^{12}$ To measure unemployment, we consider employed only those individuals that answered to have done paid work in the previous week. We also considered employed individuals if they were not present at work and they claim to have been temporarily ill, or in vacations. Every other individual is considered not employed, including those out of the labor force. The unemployment rate used in the paper is the proportion of observations that are unemployed in the sample by age. The proportion of individuals exiting unemployment is obtained as the proportion of individuals that exit unemployment from one quarter to another by age. Then we obtained the weighted average of this measure for the year. The proportion of individuals losing their jobs is obtained as the proportion of individuals that lost their job from one quarter to another, then we obtained the weighted average for this measure in the year. With this information we estimate the annual transition probabilities. The major advantage of this

\footnotetext{
${ }^{11}$ We also exclude in this sample all individuals that are interviewed by the census and that claim to work in the US.

${ }^{12}$ We also exclude individuals that left the rotating panel because they change address and the survey did not follow them. (i.e. "hogares mudados" in the data base).
} 
data set is that transitions between employment and non-employment are obtained quarter to quarter at the individual level. The major disadvantage of the data set is that it only represents the urban population of Mexico.

The fifth source of data is the CPS 1999 January to December waves. They are a representative data set of the US population. It provides also with a rotating panel on employment status, employment transitions and wages of individuals. We only include in the study individuals that claim they born in Mexico, which in total are 7.5 thousand individuals. The sample used in the study includes only males 15 to 45 years old, which are not disabled, which let us with 3.4 thousand individuals. Individuals are considered employed only if they answered to have done paid work in the previous week. They were also considered employed if they were not present at work and they claim to have been temporarily ill, or in vacations. Every other individual is considered not employed. The unemployment rate is then calculated as the proportion of observations unemployed in the sample by age. The proportion of individuals exiting unemployment is obtained as the proportion of individuals that exit unemployment from one month to another by age. Then we obtained the weighted average of this measure for the year. The proportion of individuals losing their jobs is obtained as the proportion of individuals that lost their job from one month to another, then we obtained the weighted average for this measure in the year. With this information we estimate the annual transition probabilities. The major advantage of the CPS is that it provides with month to month transitions between employment and nonemployment at the individual level. The major disadvantage is that the CPS potentially undercounts illegal Mexican migrants to the US.

Table A2 shows the number of periods that individuals appear in our different panels: the MMP103, ENEU, and the CPS. In MMP103 most observations are observed for more than 5 years. In ENEU, the individuals are distributed evenly among 2,3 and 4 periods. In the CPS most observations are found 2 to 4 periods, while very few are observed for more than 5 periods.

\section{A4. Choice of sources}

In principle, we can get all the information we need for this paper from the MMP103 data set. However, a comparison with the Mexican Census, the US census, ENEU and CPS shows that the data for wages, employment, job loss and exit from unemployment look very different, as Table A3 illustrates.

Available wages in the MMP03 are the first wage in the US, the last wage in the US and the last wage in Mexico. Wages in the US are transformed into 1999 dollars using the consumer price index. They are first transformed into annual wage income depending on their periodicity. Wage that are reported for Mexico are first transformed into annual wages depending on their periodicity, then transformed into US dollars using the exchange rate in the given year, and, finally, transformed into 1999 dollars by the consumer price index.

For wages we use Census data for both countries. We did not use ENEU data set for wages in Mexico, because this source only contains urban data, and we wanted to have a picture for the average migrant. We calculate wages from the ENEU and compare them to the wages from the Mexican census. Wages for ENEU where obtained form the wages reported in the survey, which were either monthly, biweekly, weekly or daily. They were transformed to annual income. Then divided by 9.7, which was the average exchange rate in 1999.

We use US census wages and not those of the CPS, to be consistent with the choice of data for measuring wages for Mexico. Additionally, most of the research on migration from Mexico to the US. has used Census data. We compare wages for Mexicans measured 
in the CPS with wages measured in the US census. Wages for CPS where obtained from the weekly income reported in the survey and then multiplied by 52 . In general wages in the US census are smaller than wages in the CPS Wage information from the MMP103 is very noisy, which could be related to recall bias, since these data are retrospective.

For employment rates and employment, the MMP 103 is an annual data set, in which short spells of unemployment may be not reported. Thus, we prefer to use the employment surveys for Mexico and the US, ENEU and CPS.

\section{A5. Comparison with other sources}

Our estimations of the migration rate are comparable to those of Chiquiar and Hanson (2005: 246). They show that the migration rate in 2000 for males Mexicans 16 to 25 years old was 17.58 , which is above the MMP103 migration rate of $12 \%$. For males 26 to 35 years old they estimate the migration rate at 15.49 , which is below the MMP103 migration rate of $17 \%$. Finally, for males 36 to 45 years old they estimate a migration rate of $12.21 \%$, while the MMP103 migration rate is $16 \%$. Our estimations of the unemployment rate seem higher to what has been reported in the literature, because we are including as unemployed individuals out of the labor force. Once we take into account this difference our numbers are comparable to those in the literature. Blau and Kahn (2007) report an unemployment rate for males in the US of $13 \%$, and that $6 \%$ of Mexican males in the US are out of the labor force. Their estimations are based on the CPS 1994-2003 March waves. We report an unemployment rate of $19 \%$, but this number includes individuals who are both unemployed and out of the labor force. We merge these categories to simplify our analysis.

Our estimations of probabilities of exit from unemployment and job loss probabilities are comparable to those shown by Calderon-Madrid (2000), once we take into account differences in sample and frequency reported. He shows that job loss in a given quarter of 1997 was $10.91 \%$, among males and females between 14 and 77 years old in Mexico, while the exit rate from unemployment was $12.31 \%$. In annual terms, job loss amounts to $30.66 \%$ and exit from unemployment to $34.59 \%$. Our reported job loss is smaller and our exit from unemployment higher because we look at males 15 to 45 years old. If we use CalderonMadrid (2000) sample selection rules for 1999 the job loss is equal to $33.73 \%$, while exit from unemployment is $46.66 \%$ for 1999 .

Card and Lewis (2007) show that the mean hourly wage for Mexicans in the 2000 US census was 12.89 dollars per hour for males 16 to 45 years old. Using our sample, which is different from their sample in that we exclude disabled individuals, generates an average annual wage income of $\$ 16,816$ for that year. If individuals worked 52 weeks and 40 hours per week, that annual wage income is equivalent to approximately 8.08 dollars per hour. We believe this implies that leisure choices are potentially important, since it is obvious that individuals must be working less than full time shifts. However, and in-depth analysis is beyond the scope of this paper and is left for future research. 
International Job Search. Rendon and Cuecuecha. December 2007

\section{References}

Angelucci, M. (2002), Us Border Enforcement and the Inflow-outflow of Mexican Illegal Immigration. University College London, Working Paper.

Aydemir, A. and Robinson, C. (2006), Return and Onward Migration among Working Age Men. Analytical Studies Branch Research Paper Series. Family and Labor Studies Division, Statistics Canada No 273.

Bencivenga, V. and Smith, B. (1997), 'Unemployment, Migration and Growth', Journal of Political Economy 105(3), 582-608.

Blau, D. F. and Kahn, L. M. (2007), Gender Assimilation among Mexican Americans, in G. J. Borjas, ed., 'Mexican Immigration to the United States', The University of Chicago Press, Chicago, pp. 57-106.

Borjas, G. and Bratsberg, B. (1996), 'Who Leaves? The Outmigration of the Foreign Born', Review of Economics and Statistics 78(1), 165-176.

Calderón-Madrid, A. (2000), Job Stability and Labor Mobility in Urban Mexico: A Study Based on Duration Models and Transition Analysis. Interamerican Development Bank. Research Network Working Paper R-419. Analytical Studies Branch Research Paper Series.

Card, D. and Lewis, E. (2007), The Difussion of Mexican Immigrants during the 1990s: Explanations and impacts, in E. G. J. Borjas, ed., 'Mexican Immigration to the United States', The University of Chicago Press, Chicago, pp. 193-228.

Chiquiar, D. and Hanson, G. (2005), 'International Migration, Self Selection, and the Distribution of Wages', Journal of Political Economy 113(2), 239-281.

Colussi, A. (2006), Migrants'networks: An Estimable Model of Illegal Mexican Migration. University of Western Ontario. Working Paper.

Cuecuecha, A. (2006), Why Do People Go Home Again? Disappointment Theory and Target Saving Theory Revisited. Instituto Tecnológico Autónomo de México. Working Paper.

Delechat, C. (2001), 'International Migration Dynamics: The Role of Experience and Social Networks', Labour 15(3), 457-486.

Djajic, S. and Milbourne, R. (1988), 'A General Equilibrium Model of Guest Worker Migration: A source country perspective', Journal of International Economics 25, 335-331.

Dustmann, C. (1997), 'Return Migration, Uncertainty and Precautionary Savings', Journal of Development Economics 52, 295-316.

Dustmann, C. (2003), 'Return Migration, Wage Differentials, and the Optimal Migration Duration', European Economic Review 47, 353-369.

Dustmann, C. and Kirchkamp, O. (2002), 'The Optimal Migration Duration and Activity Choice After Remigration', Journal of Development Economics 67, 351-372. 
Frenkel, R. and Ross, J. (2004), Unemployment, Macroeconomic Policy and Labor Market Flexibility: Argentina and Mexico in the 1990ts. Kellog Institute for International Studies, University of Notre Dame. Working Paper 309.

Gemici, A. (2007), Family Migration and Labor Market Outcomes. University of Pennsylvania, mimeo.

Harris, J. and Todaro, M. (1970), 'Migration, Unemployment, and Development: A Two Sector Analysis', American Economic Review 30(1), 126-142.

Haslag, J., Guzman, M. and Orrenious, P. (2004), Accounting for Fluctuations in Social Network Usage and Migration Dynamics. University of Missouri, Working Paper.

Heckman, J. and Pages-Serra, C. (2000), 'The Cost of Job Security Regulation: Evidence from Latin American Labor Markets', Economía 1(1), 109-154.

Hendricks, L. (2001), 'The Economic Performance of Immigrants: A Theory of Assortative Matching', International Economic Review 42(2), 417-449.

Herzog, H. and Schottman, A. (1982), 'Migration Information, Job Search and the Remigration Decision', Southern Economic Journal 50(1), 43-56.

Hill, J. K. (1987), 'Immigrant Decisions Concerning Duration of Stay and Migratory Frequency', Journal of Development Economics 25, 221-234.

Jasso, G. and Rosenzweig, M. (1982), 'Estimating the Emigration Rates of Legal Immigrants Using Administrative and Survey Data: The 1971 Cohort of Immigrants to the United States', Demography 19(3), 279-290.

Katz, E. and Stark, O. (1987), 'International Migration Under Asymmetric Information', Economic Journal 97(387), 718-726.

Kennan, J. and Walker, J. R. (2006), The Effect of Expected Income on Individual Migration Decisions. University of Wisconsin-Madison, mimeo.

Lindstrom, D. P. (1996), 'Economic Opportunity in Mexico and Return Migration from the United States', Demography 33(3), 357-374.

Maloney, W. (1997), Are LDC Labor Markets Dualistic? Washington, D.C., US:World Bank.

Massey, D., Arango, J., Hugo, G., Kouaoci, A., Pellegrino, A. and Taylor, J. E. (1993), 'Theories of International Migration: A Review and Appraisal', Population and Development Review 19(4), 699-751.

Mesnard, A. (2004), 'Temporary Migration and Capital Markets Imperfections', Oxford Economic Papers 56, 242-262.

Piore, M. (1979), Birds of Passage, Cambridge University Press, New York.

Press, W. H., Teutolsky, S. A., Vetterling, W. T. and Flannery, B. P. (1992), Numerical Recipes in FORTRAN: The Art of Scientific Computing, Cambridge University Press, New York. 
Raffalhüschen, B. (1992), 'Labor Migration in Europe: Experiences from Germany after Unification', European Economic Review 36, 1453-1473.

Rendon, S. (2006), 'Job Search and Asset Accumulation under Borrowing Constraints', International Economic Review 47(1), 233-263.

Rendon, S. (2007), 'Does Wealth Explain Black-White Differences in Early Employment Careers?', Journal of Business and Economic Statistics 25(4), 484-500.

Reyes, B. (1997), Dynamics of Immigration: Return Migration to Western Mexico, Public Policy Institute of California, San Francisco.

Sjaastad, L. (1962), 'The Costs and Returns of Human Migration', Journal of Political Economy 70(5), 80-93.

Stark, O. (1984), 'Rural to Urban Migration in ldc's', Economic Development and Cultural Change 32(3), 475-486.

Stark, O., Helmenstein, C. and Yegorov, Y. (1997), 'Migrants'savings, Purchasing Power Parity, and The Optimal Duration of Migration', International Tax and Public Finance 4, 307-324.

Stark, O. and Yitzhaki, S. (1988), 'Labour Migration as a Response to Relative Deprivation', Journal of Population Economics 1(1), 57-70.

Todaro, M. and Maruszko, L. (1987), 'Illegal Immigration and us Immigration Reform: A Conceptual Framework', Population and Development Review 13(1), 101-114.

Warren, R. and Peck, J. M. (1980), 'Foreign Born Emigration from the United States: 1960 to 1970 ', Demography 17(1), 71-84.

Yang, D. (2006), 'Why Do Migrants Return to Poor Countries? Evidence from Philippine Migrants'responses to Exchange Rate Shocks', Review of Economics and Statistics 88(4), 715-735. 
Table 1: Descriptive Statistics. Wages in US dollars. Rates and flows in \%

\begin{tabular}{|c|c|c|c|c|c|c|c|c|}
\hline \multirow{3}{*}{$\begin{array}{l}\text { Country } \\
\text { Variable }\end{array}$} & \multicolumn{4}{|c|}{ Mexico } & \multicolumn{4}{|c|}{ United States } \\
\hline & \multirow{2}{*}{ Source } & \multicolumn{3}{|c|}{ Age } & \multirow[t]{2}{*}{ Source } & \multicolumn{3}{|c|}{ Age } \\
\hline & & $16-25$ & $26-35$ & $36-45$ & & $16-25$ & $26-35$ & $36-45$ \\
\hline Migration rate-stock & & & & & MMP03 & 11.90 & 17.44 & 15.68 \\
\hline Migration flow from & MMP03 & 3.77 & 3.07 & 2.03 & MMP03 & 17.61 & 13.17 & 10.10 \\
\hline Annual Wage & Mx. Cens & 3073 & 4997 & 5779 & US Cens & 9279 & 18651 & 21793 \\
\hline Annual Log wage & Mx. Cens & 7.69 & 8.11 & 8.20 & US Cens & 9.09 & 9.74 & 9.87 \\
\hline Standard Deviation & Mx. Cens & 0.64 & 0.79 & 0.89 & US Cens & 0.92 & 0.76 & 0.82 \\
\hline Unemployment rate & ENEU & 34.85 & 4.43 & 3.72 & CPS & 26.49 & 6.69 & 9.82 \\
\hline Job taking & ENEU & 60.17 & 95.04 & 94.81 & CPS & 74.70 & 92.95 & 85.89 \\
\hline Job loss & ENEU & 29.67 & 3.73 & 3.31 & CPS & 22.08 & 6.42 & 8.74 \\
\hline Job-to-Job & MMP03 & 10.77 & 6.88 & 4.73 & MMP03 & 27.46 & 19.38 & 15.09 \\
\hline
\end{tabular}

Table 2: Parameter Estimates. Standard errors in small fonts

\begin{tabular}{|c|c|c|c|c|c|}
\hline \multirow{2}{*}{$\begin{array}{c}\text { Parameter } \\
\text { Unemployment Transfers: }\end{array}$} & \multirow{2}{*}{$\widehat{\widehat{\Theta}}$} & \multicolumn{2}{|c|}{ Mexico } & \multicolumn{2}{|c|}{$\mathrm{USA}$} \\
\hline & & 24.40 & $(2)$ & 239.68 & $(45)$ \\
\hline Arrival rate unemployed: base & $\lambda_{0}$ & 0.4090 & $(0.0241)$ & 0.8645 & $(0.0527)$ \\
\hline growth: & $\alpha_{\lambda}$ & 0.2110 & $(0.0193)$ & 0.0049 & $(0.0002)$ \\
\hline Arrival rate employed: base & $\pi_{0}$ & 0.1716 & $(0.0316)$ & 0.6949 & $(0.0473)$ \\
\hline growth: & $\alpha_{\pi}$ & 0.0012 & $(0.0014)$ & 0.0033 & $(0.0001)$ \\
\hline Layoff rate: base & $\theta_{0}$ & 0.7686 & $(0.0356)$ & 0.3755 & $(0.0684)$ \\
\hline growth: & $\alpha_{\theta}$ & -0.2092 & $(0.0042)$ & -0.0620 & $(0.0001)$ \\
\hline Mean of base logwages: & $\mu$ & 6.9051 & $(0.7015)$ & 8.1832 & $(0.9356)$ \\
\hline growth linear: & $\alpha_{1}$ & 0.0942 & $(0.0043)$ & 0.0934 & $(0.0026)$ \\
\hline growth quadratic: & $\alpha_{2}$ & -0.0020 & $(0.0036)$ & -0.0021 & $(0.0042)$ \\
\hline St. Deviation of logwages: & $\sigma$ & 0.8667 & $(0.3373)$ & 0.8110 & $(0.0446)$ \\
\hline Cost of Migration & $c$ & 549.63 & $(94.54)$ & 22.79 & $(147.46)$ \\
\hline Attachment to origin: & $C_{\psi}$ & & 1452.48 & $(46.7472)$ & \\
\hline Coefficient of risk aversion: & $\gamma$ & & 0.5591 & $(0.0374)$ & \\
\hline Mean of initial logwealth: & $\mu_{0}$ & & 10.5367 & $(3.5830)$ & \\
\hline St. Devation of initial logwealth: & $\sigma_{0}$ & & 2.0881 & $(1.1230)$ & \\
\hline Criterion value & $S$ & \multicolumn{4}{|c|}{117.6244} \\
\hline
\end{tabular}


Table 3: Goodness of fit tests: $\chi^{2}$ and $R^{2}$

\begin{tabular}{lccc}
\hline \multicolumn{1}{c}{ Country } & Mexico & United States \\
\hline \hline Migration rate & Statistic & & \\
Migration flows (from) & $\chi^{2}$ & & 0.92903 \\
Annual Wage & $\chi^{2}$ & 3.89290 & 0.55799 \\
Annual Log wage & $R^{2}$ & 0.99999 & 0.99999 \\
Standard Deviation & $R^{2}$ & 0.99997 & 0.99996 \\
Unemployment rate & $R^{2}$ & 0.92304 & 0.94679 \\
Exit from Unemployment & $\chi^{2}$ & 5.44038 & 17.41246 \\
Job loss & $\chi^{2}$ & 1.30834 & 1.45616 \\
Job-to-Job Transitions & $\chi^{2}$ & 11.23685 & 11.52497 \\
\hline \hline
\end{tabular}

Note. Critical values are: $\chi_{(29)}^{2}=42.5570$, at $5 \%$ and $\chi_{(29)}^{2}=52.3356$, at $0.5 \%$ significance level. 
International Job Search. Rendon and Cuecuecha. December 2007

Table 4: Regime Changes:

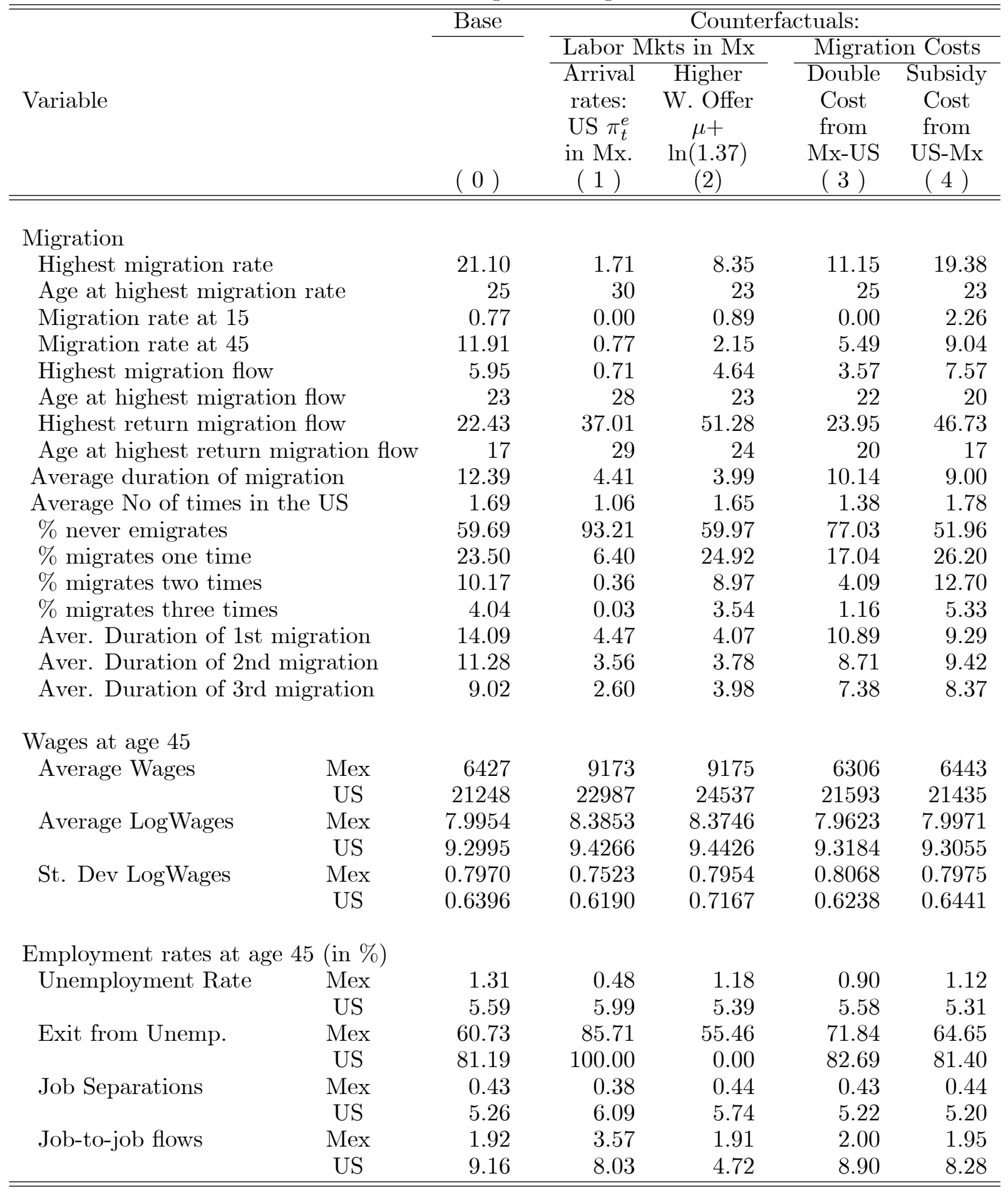


Table A1: Sample Selection (Individuals)

\begin{tabular}{lrrrrr}
\hline \hline & MMP & Mex. Census & US Census & ENEU & CPS \\
\hline \hline & & & & & \\
All & 15,379 & $4,938,130$ & 234,159 & 234,423 & 7,477 \\
15 to 45 & 8,191 & $2,263,840$ & 172,778 & 164,286 & 5,603 \\
Excluding disabled & 8,172 & $1,693,627$ & 133,977 & 157,463 & 5,570 \\
Individuals with 2+ periods & 8,172 & - & - & 112,649 & 3,402 \\
\hline \hline
\end{tabular}

Table A2: Balance of the Panels (Individuals)

\begin{tabular}{cccc}
\hline \hline & \multicolumn{3}{c}{ Data set } \\
\cline { 2 - 4 } Variable & MMP & $\begin{array}{c}\text { ENEU } \\
\text { Quarterly }\end{array}$ & $\begin{array}{c}\text { CPS } \\
\text { Monthly }\end{array}$ \\
\hline \hline & Annual & (12, & \\
$\mathrm{N}$ & 8172 & 112,649 & 3,402 \\
Periods & $\%$ & $\%$ & $\%$ \\
2 & 0.00 & 25.88 & 23.07 \\
3 & 0.01 & 26.68 & 20.43 \\
4 & 0.01 & 47.44 & 54.85 \\
$5+$ & 99.98 & - & 1.65 \\
\hline \hline
\end{tabular}

Table A3: Descriptive Statistics. Choice of Sources

\begin{tabular}{|c|c|c|c|c|c|c|c|c|}
\hline \multirow{3}{*}{$\begin{array}{l}\text { Country } \\
\text { Variable }\end{array}$} & \multicolumn{4}{|c|}{ Mexico } & \multicolumn{4}{|c|}{ United States } \\
\hline & \multirow[t]{2}{*}{ Source } & \multicolumn{3}{|c|}{ Age } & \multirow[t]{2}{*}{ Source } & \multicolumn{3}{|c|}{ Age } \\
\hline & & $16-25$ & $26-35$ & $36-45$ & & $16-25$ & $26-35$ & $36-45$ \\
\hline Annual Log wage (dollars) & $n_{\mathrm{Suls}}$ & 7.69 & 8.11 & 8.20 & ensus & 9.09 & 9.74 & 9.87 \\
\hline Standard Deviation & in & 0.64 & 0.79 & 0.89 & Census & 0.92 & 0.76 & 0.82 \\
\hline Annual Log wage (dollars) & NEU & 9.04 & 9.51 & 9.55 & CPS & 9.46 & 9.86 & 9.96 \\
\hline Standard Deviation & NEU & 0.75 & 0.75 & 0.95 & $\mathrm{CF}$ & 0.52 & 0.48 & 0.47 \\
\hline Log wage (dollars) & MP & 8.47 & 8.40 & 8.48 & MMP & 10.08 & 10.01 & 9.83 \\
\hline Standard Deviation & MMP & 2.82 & 3.01 & 2.99 & MMP & 0.85 & 0.76 & 0.61 \\
\hline Unemployment rate $(\%)$ & U & 34.85 & 4.43 & 3.72 & $\mathrm{CP}$ & 26.49 & 6.69 & 9.82 \\
\hline Exit from Unemployment (\%) & ENEU & 60.17 & 95.04 & 94.81 & CPS & 74.70 & 92.95 & 85.89 \\
\hline Job loss $(\%)$ & ENEU & 29.67 & 3.73 & 3.31 & CPS & 22.08 & 6.42 & 8.74 \\
\hline Unemployment rate (\%) & MMP & 1.73 & 0.67 & 1.17 & MMP & 1.17 & 0.37 & 0.65 \\
\hline Exit from Unemployment (\%) & MMP & 20.55 & 19.74 & 8.24 & MMP & 26.90 & 36.06 & 23.17 \\
\hline Job loss $(\%)$ & MMP & 0.22 & 0.12 & 0.16 & MMP & 0.14 & 0.07 & 0.21 \\
\hline
\end{tabular}




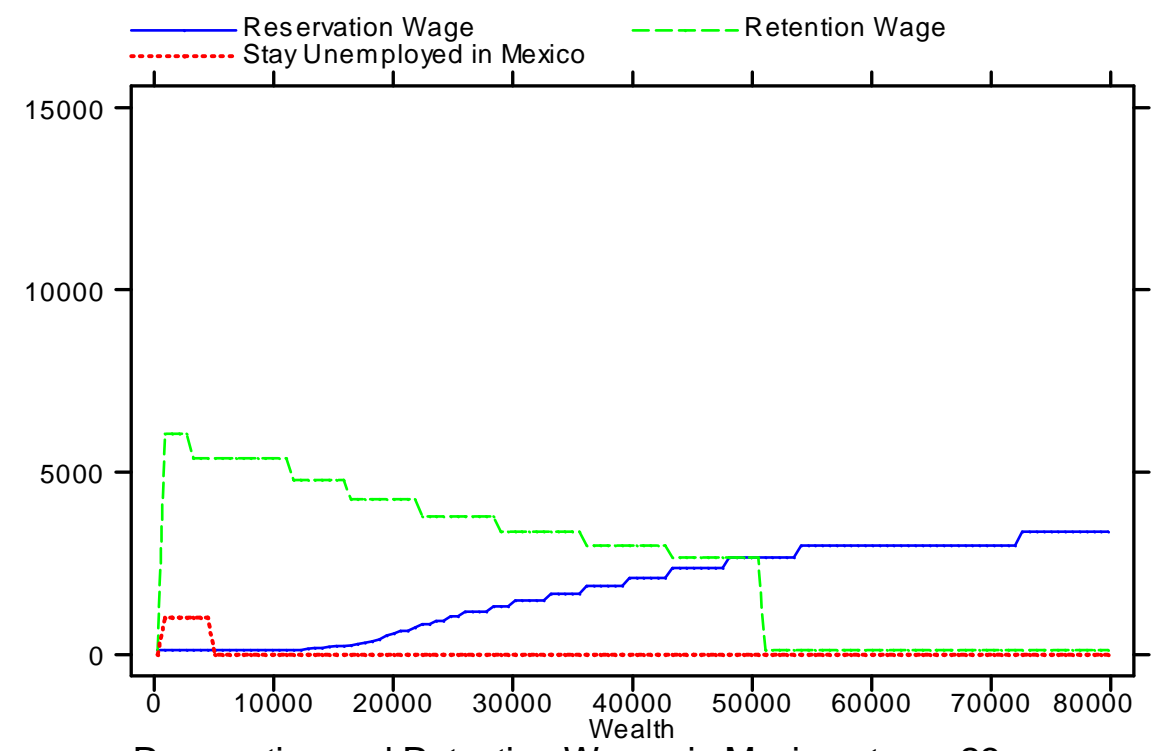

Reservation and Retention Wages in Mexico at age 23

Figure 1: Mexico: $\omega_{11}^{*}(A, 0)$ and $\omega_{11}^{* *}(A, 0)$, and rescaled Indicator funtion $I_{11}^{m}(A, 0)$.

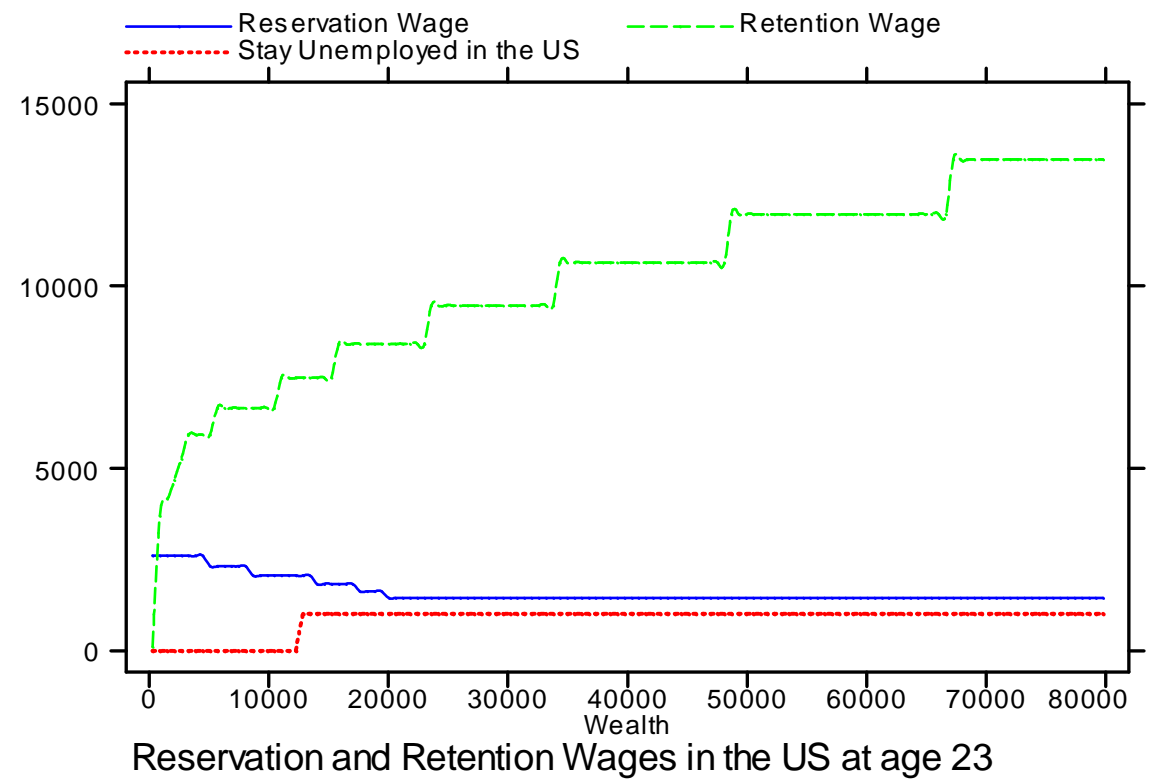

Figure 2: USA: $\omega_{11}^{*}(A, 1)$ and $\omega_{11}^{* *}(A, 1)$, and rescaled Indicator funtion $I_{11}^{m}(A, 1)$ 

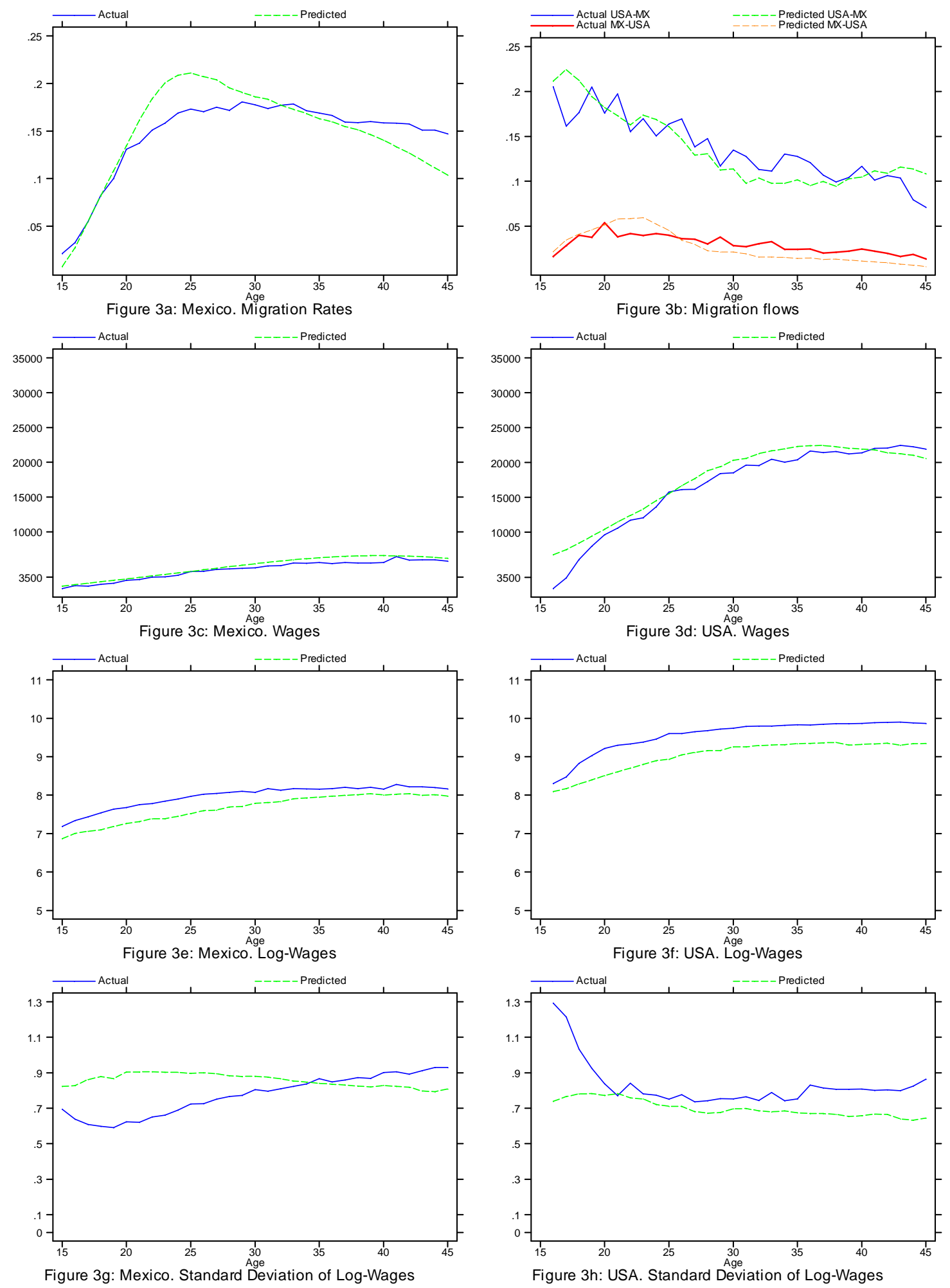

Figure 3: Actual and Predicted Migration Rates and Wages 

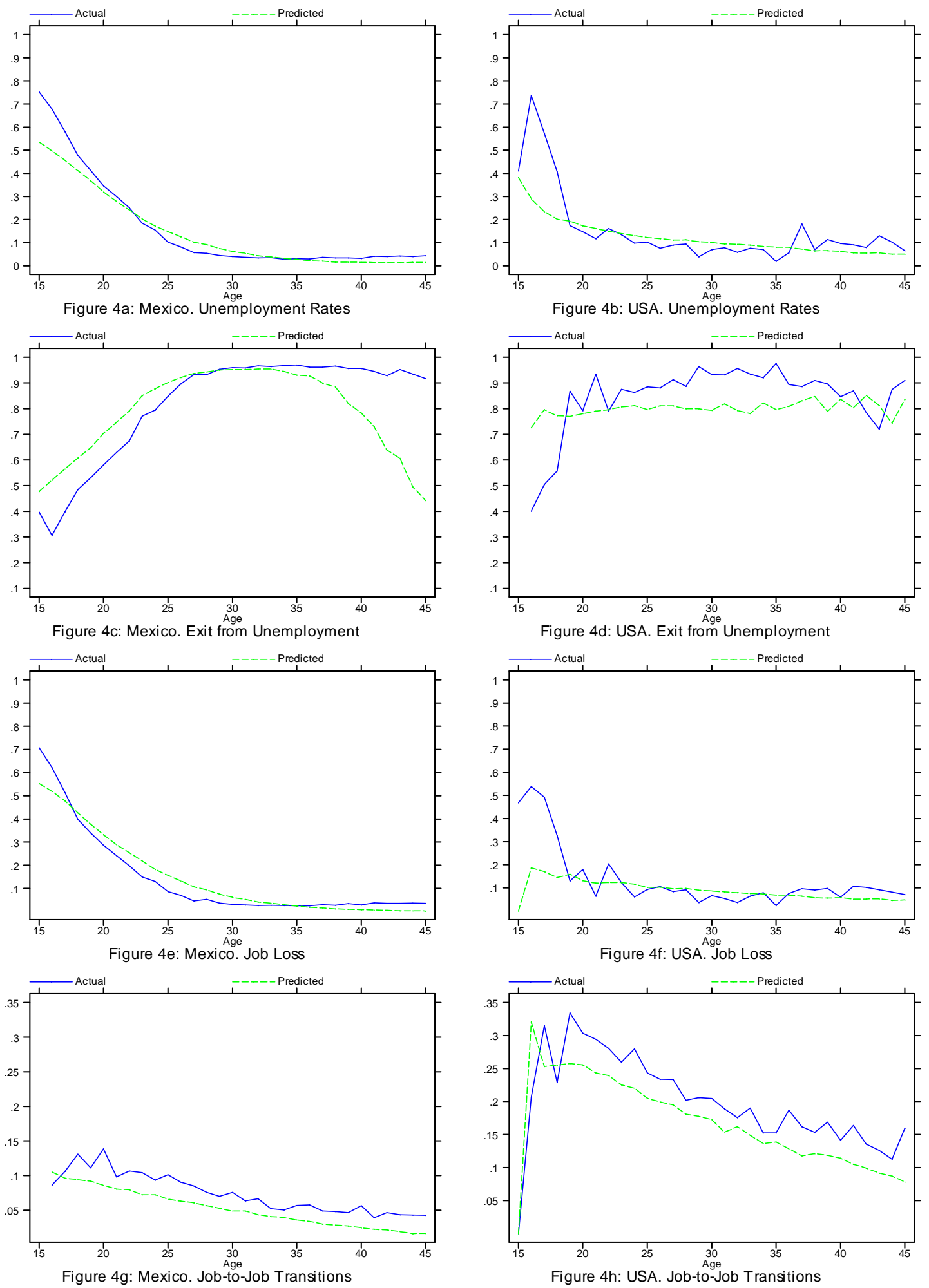

Figure 4: Actual and Predicted: Employment Status and Employment Transitions 

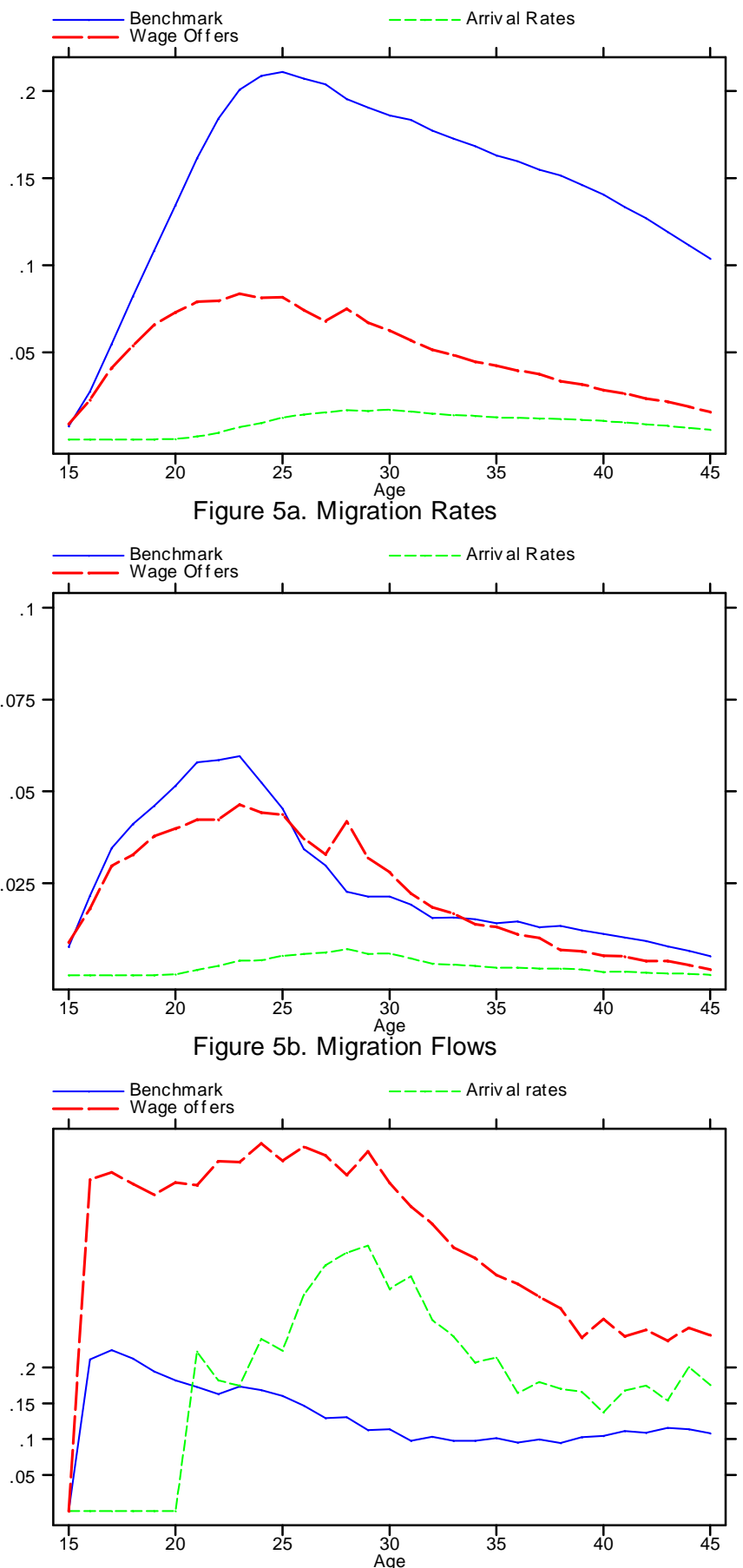

Figure 5c. Return Migration Flows

Figure 5: Regime Changes: Labor Market Improvements in Mexico 

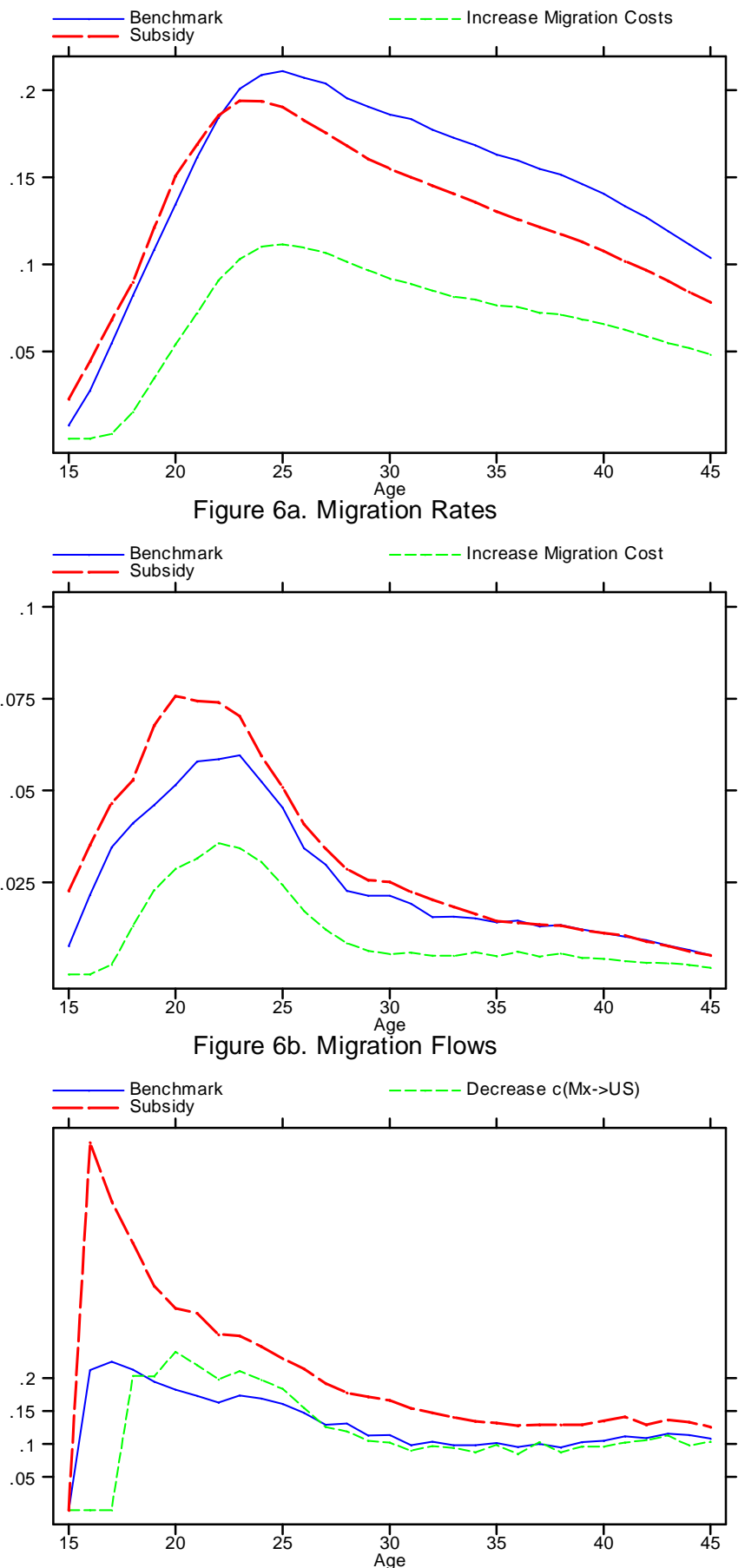

Figure 6c. Return Migration Flows

Figure 6: Regime Changes: Migration Costs Variations 